\title{
A Case Study About Accelerating Expansion of Restaurants Industry in Saudi Arabia
}

\author{
Maroua M. Bouznif (Corresponding author) \\ College of Business Administration, King Saud University, P.O. Box: 51049, Riyadh \\ 11543, Saudi Arabia \\ E-mail: boznif_marwa@hotmail.com \\ Jawahir AlMudbel \\ College of Business Administration, King Saud University, Riyadh, Saudi Arabia \\ E-mail: j.almudbal@gmail.com \\ Shadden Almarshed \\ College of Business Administration, King Saud University, Riyadh, Saudi Arabia \\ E-mail: shalmarshed@yahoo.com \\ Ibtissem Mohamed Ben Ajmi \\ Institut des Hautes Etudes Commerciales (IHEC) - Cartage University. Tunis, Tunisia \\ E-mail: benajmiibtissem@yahoo.com
}

Received: May 11, 2018 Accepted: May 25, 2018 Published: June 14, 2018

doi:10.5296/bms.v9i1.13283～URL: https://doi.org/10.5296/bms.v9i1.13283

\begin{abstract}
Restaurants have recently witnessed a fast growth in Saudi Arabia. Though this growth considers being relatively recent, it is widely observed by everyone. This case study illustrates the progress of restaurants in Saudi Arabia, factors influencing restaurants
\end{abstract}


expansion, some strategic and tactical issues in managing restaurants, restaurants classification. Besides, it describes the key players' restaurants, presents some new trends and challenges attached to their growth and finally where the restaurants are heading to.

Keywords: Case study, Saudi Arabia, Restaurants, Cafe, Managing restaurants, Restaurant expansion 


\section{Ml Macrothink}

\section{Introduction}

The culture of eating out at the restaurants in Saudi Arabia is still relatively new. Although there is an early emergence of consuming soft drinks and Turkish sweets, the notion of fast food restaurants was delayed to more than four decades (www.alriyadh.com, 2012). In the past Saudis did eat food just at their homes or at visitations where it was prepared by their housewives. The initial reason of restaurants beginning in KSA was for traveling purposes, where travelers found a place to eat and rest in, unlike city residents who were facilitated within a permanent place to live in (www.alriyadh.com, 2014). Today the investment in that sector has rapidly increased by more than 17 billion Saudi Riyals (SR) wherein it offers many jobs opportunities to Saudis (www.slaati.com, 2015).

This case study sheds light on some strategic and tactical issues impacting the rapid growth of restaurants sector as a leisure activity in KSA. In addition, it introduces some new trends such as: shift toward diet centers and healthy food, electronic restaurants though social media, and fully female-services restaurants. On the other hand, it clarifies some challenges that facing this sector like, stiff competition between restaurants, an increase in life expenditures and inflation, and finally health problems. As figure 1 (Restaurants landscape in Saudi Arabia) illustrates the pattern of this case study which was adopted from: \{What, Who, How And Where: Retailing In Saudi Arabia\} with some modifications that fit the situation of Saudi restaurants (Kukko \& Al-Aali, 2015).

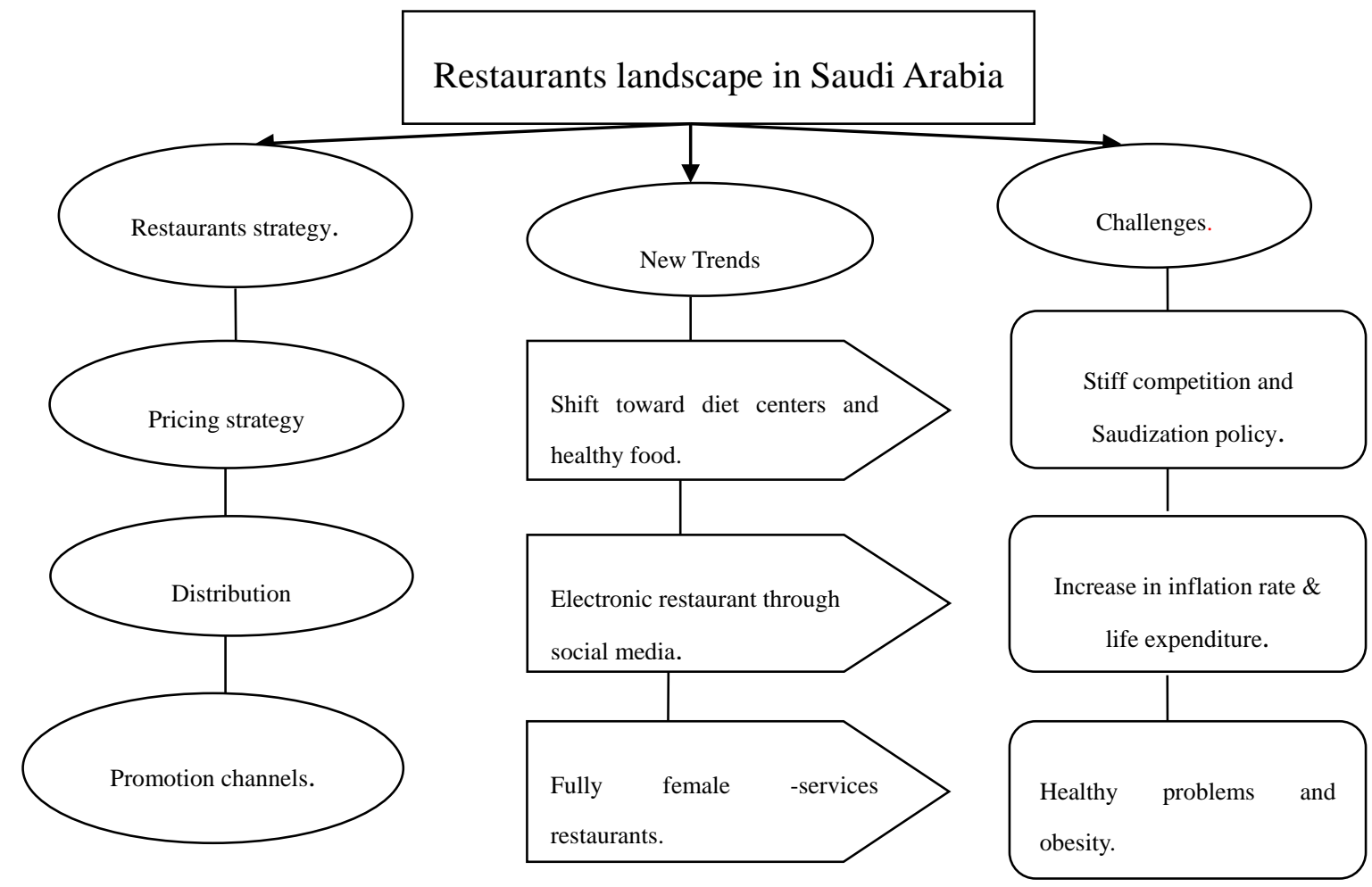

Source: What, Who, How And Where: Retailing In Saudi Arabia

Figure 1. Restaurants Landscape in Saudi Arabia 
An estimated study has recently conducted about the returns from restaurants and cafes sector reported 23 billion Saudi Riyals (SR) in 2015 (www.alriyadhtrading.com, 2018). According to Riyadh Chamber of Commerce and Industry; restaurants sector classifies by their market contribution into three segments: fast food restaurants $56 \%$, full service restaurants $35 \%$, and coffee shops 8\% (www.alriyadhtrading.com, 2018). Therefore, some businessmen shift toward investing more and more in that industry because it is a lucrative trade.

\section{The Progress of Restaurants in Saudi Arabia}

Makkah was the first city in Saudi Arabia where restaurants initially appeared for pilgrims' services who came to perform Hajj (Pilgrimage). In light of that, "Abu Rashid Cafe" was the oldest recorded restaurant at King Abdulaziz era, serving Pumpkin Sauce, where it was located at the back of his royal palace in Riyadh (www.alriyadh.com, 2014). After that many restaurants start to appear in Riyadh like AlOjela Restaurant, Sahara Hotel Restaurant, AlQabani Restaurant, and AlHella Restaurant. Thus, it can be inferred that the restaurants function was simply as cafes where people bring meat with them to be cooked by waiters.

Basically the services of restaurants were by the command of consumers, and they were exclusively for males' services, so no females were allowed to go to restaurants or cafes at that time. Initially, the services of restaurants were restricted only to individual males. In nineties, a new style of "family restaurants" started to show up in KSA and since that time till today Saudi families enjoy eating out at restaurants (www.alriyadh.com, 2012). Notably the point of Saudi community view about restaurants has finally changed after it was a disgrace and shame on individuals to go such places.

Surprisingly, one of the most major shift in the history of Saudi restaurants happened when the emergence of hamburger restaurants was concurrent with Shawarma restaurants in 1980, however, Pizza restaurants were delayed to appear at the end of the eighties. Later, in the early nineties, Saudi discovered a new trend of coffee shops where they taste different flavors of Turkish and Italian coffee. Ultimately, different types of global cuisines begin to flourish in Saudi Arabia.

Restaurants are annually increasing across whole the regions of Saudi Arabia. According to the General Authority for Statistics (https://www.stats.gov.sa); there are about 15,782 restaurants in 2014. Apparently Makkah has almost the largest figure of Saudi restaurants by which it has 5,187 restaurants in 2014. Then, Riyadh (the capital city) is the second city after Makkah by which it has 3,245 restaurants (See table 1 which represents numbers of Saudi restaurants by regions).

As the agile expansion of restaurants market increases, a conducted study by the Chamber of Hospitability Commission in Jeddah and the Ministry of Labor aims to classify restaurants sectors in Saudi Arabia. According to Mr. Makki, there are five possible targeted restaurants: (i) fine dining restaurants; (ii) fast food restaurants; (iii) traditional food restaurants; (iv) fine dining and fast food restaurants; and finally (v) cafes (arabic.arabianbusiness.com, 2016). Another key point, there is a potential sub-classification to restaurants which differs in term 
of types, sizes, classes, cuisines, and the geographical locations of the restaurants.

Table 1. Number of Saudi Restaurants by Regions

\begin{tabular}{|l|c|c|c|}
\hline $\begin{array}{l}\text { Geographical } \\
\text { Zones }\end{array}$ & $\mathbf{2 0 1 2}$ & $\mathbf{2 0 1 3}$ & $\mathbf{2 0 1 4}$ \\
\hline Riyadh & 2,968 & 3,082 & 3,245 \\
\hline Makkah & 4,908 & 5,056 & 5,187 \\
\hline Medina & 993 & 1,023 & 1,049 \\
\hline AlQassim & 615 & 634 & 650 \\
\hline Eastren Province & 2,698 & 2,787 & 2,857 \\
\hline Asir & 781 & 805 & 826 \\
\hline Tabuk & 395 & 407 & 417 \\
\hline Hail & 256 & 264 & 271 \\
\hline Nothern Boardes & 189 & 195 & 200 \\
\hline Jizan & 460 & 474 & 486 \\
\hline Najran & 228 & 235 & 241 \\
\hline AlBaha & 190 & 196 & 201 \\
\hline AlJouf & 144 & 148 & 152 \\
\hline Total & 14,825 & 15,306 & 15,782 \\
\hline
\end{tabular}

Source: https://www.stats.gov.sa

\section{Factors Influencing Restaurants Expansion in Saudi Arabia}

\subsection{International Workforce}

Non-Saudis represent more than one-third of Saudi population. Basically in the past the main dish in KSA was just restricted to Kabsa that was cooked at homes till Yemenis introduced the first (Kabsa and Mandi restaurants) where cheaper and convenient rice meals were served to Saudis (www.alriyadh.com, 2014). In addition, some other nationalities have a great impact in Saudi restaurants are Pakistani, Indian, Egyptian, Sudanese, and Syrian because the accounts a large portion of workforce. As table 2 (Workforce in Saudi Arabia) shows the percentage of international workforce in Saudi Arabia, it is adopted and scheduled from this website (www.alriyadh.com, 2014).

Table 2. Workforce in Saudi Arabia

\begin{tabular}{|l|c|c|}
\hline Rank & Nationality & Percentage \\
\hline First & Indian & $19.4 \%$ \\
\hline Second & Pakistani & $14.5 \%$ \\
\hline Third & Bangladeshi & $14.4 \%$ \\
\hline Fourth & Egyptian & $14.3 \%$ \\
\hline Fifth & Philippine & $11.3 \%$ \\
\hline Sixth & Yemeni & $5.07 \%$ \\
\hline Seventh & Indonesian & $4.19 \%$ \\
\hline Eighth & Sudanese & $2.5 \%$ \\
\hline
\end{tabular}

Source: www.alriyadh.com/976708 
Interestingly, at breakfast time the majority of Saudis have (Tamees bread made by Pakistanis) along with (Ful Medames and Falafel made by Sudaneses and Egyptians). Another notable phenomena imported from Asian cuisine are the abundance of (Biryani, Bukari, and Kabuli Rice) restaurants that existed everywhere in KSA. Equally important, in 1980 (Shawarma restaurants) started to appear in KSA by Syrians, Saudis loved that kind of sandwiches and then Syrian cuisine started to become familiar to Saudis.

\subsection{High Level of Consumerism in KSA}

Saudi Arabia is one of the richest countries by it is petroleum sector sources that account one quarter of the world reserves (Tunclap, 1991). Consequently, that leads to increase in the disposable income for Saudi families which stimulate restaurants industry to expand more rapidly. The spending on restaurants sector by Saudi families reached more than 33 billion SR (www.cnbcarabia.com, 2014). As a result, Saudi Arabia has become amongst the highest consumer-oriented communities in the world (Assad, 2008). Furthermore, KSA is also ranked the fourth consuming country in the world where restaurants and hotels sectors are the best destinations to Saudis consumers (www.al-madina.com, 2014).

\subsection{Increases in Population Growth}

Generally, the increase in population leads to continual pressure into service sectors in order to serve people more efficiently. General Authority for Statistics reports an overall increase in the total population in Saudi Arabia in 2017. As it illustrated in table 3 (Population in Saudi Arabia), the total population reached more than 33 million by the end of 2017 (www.argaam.com, 2017). Therefore, that would open countless opportunities to businessmen to improve and provide more restaurants for investment to fulfill consumers' needs and raise the satisfaction level.

Table 3. Population in Saudi Arabia

\begin{tabular}{|l|c|c|c|}
\hline Year & Saudi population & Non-Saudi population & Total population \\
\hline 2014 & 20.70 & 10.07 & 30.77 \\
\hline 2015 & 21.12 & 10.40 & 31.52 \\
\hline 2016 & 20.06 & 11.68 & 31.74 \\
\hline $2017^{*}$ & 20.43 & 12.18 & 32.61 \\
\hline
\end{tabular}

* An estimated numbers forecasted based on 2016 figures.

Source: https://www.argaam.com/ar/article/articledetail/id/488235

\subsection{Changes in Lifestyle Pattern}

\subsubsection{Shift to Urbanized Society}

The process of making Saudi people shift from dining at home, houses of friends, or relatives to restaurants and cafes was not an easy process; therefore, it was gradually evolved. The food industry in Saudi Arabia at its beginning was very basic. Restaurants started out with providing traditional food and basic Arab dishes like: (Rise, Ful, Tamis and Shawrma 


\section{Macrothink}

Sandwiches) that where common to Saudi culture and expanding from there to be more international.

\subsubsection{Shift toward Nuclear Family}

Saudi families in the past, at the time of our great grandparents, used to live together in one small house containing: (The grandparents, their siblings, their siblings' spouses, and their grandkids) all underneath one roof. With the help of economy, globalization and technology progress Saudi families are now drifting towards a nuclear family phenomenon for more privacy and better money management.

\subsubsection{More Women in Workplace}

Numbers of Saudi Women in the workplace have increased noticeably in the last 15 years. Thus, Saudi and Non-Saudi female employees account about $10.1 \%$ and $6.5 \%$ respectively (See figure 2: Distribution of Saudi's and Non Saudi's Population in the Workforce). These statistics where last updated in 2016 by the General Authority for Statistics Website (http://www.stats.gov.sa/ar). Under this respect, women work for either straight shifts (from 7.30 A.M. to 3.30 P.M.) or split shifts from (8.00 A.M. to 12. P.M. - 4.00 P.M. to 8.00 P.M.). It would be hard for them to cook at home especially with hectic nature of work that makes restaurants an easy means to have their meals. So from their prospective, it would be more economic, effortless, and time saving to eat or order their meals from restaurants instead of cooking at home.

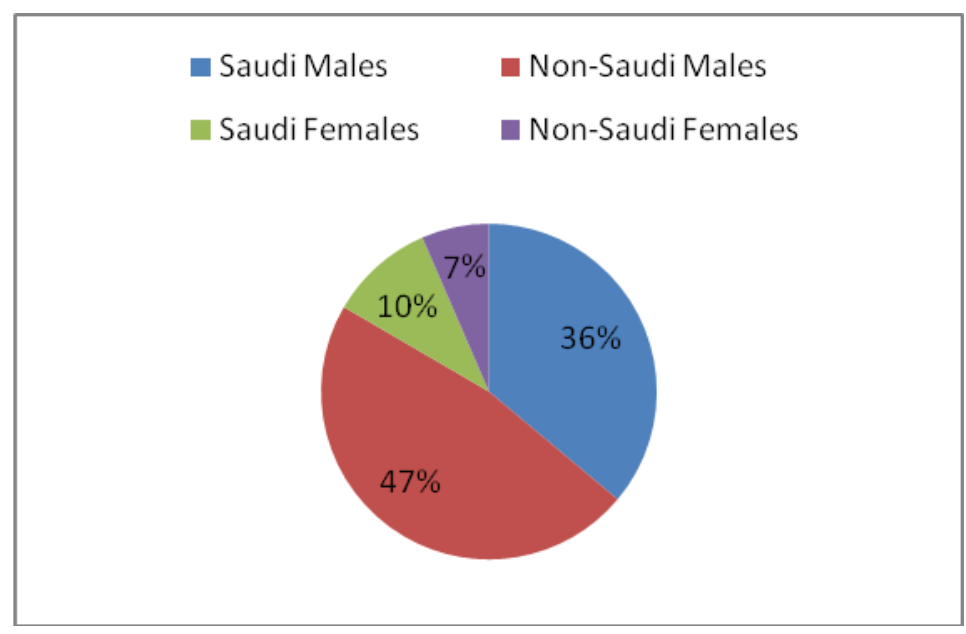

Source: $\underline{\text { htp: }: / w w w . s t a t s . g o v . s a / a r ~}$

Figure 2. Distribution of Saudis and Non-Saudis Population in Workforce

\subsubsection{More Young Teenagers Love Eating Out}

Generally, teenagers worldwide are known for their love for new things and to be specific Saudi teenagers are fond of restaurants, especially fast food which it becomes a clear phenomenon. They are very trendy and love experimenting and always want to lead in everything. When it comes to restaurants, they are the majority customers. As soon as a new 
restaurant opens, they go rushing to be the first tasters. And now with new technology and social media, they post pictures of their dishes in Snapchat and check in their Path accounts to let everyone knows that they have "Been There and Done That" which is very helpful for marketing these days.

\subsubsection{Restaurants Are the Only Entertainment Activity}

Entertainment in Saudi Arabia is very limited as there are no cinemas to go to watch movies or other activities like concerts and carnivals. The only entertainment options are inside gatherings or outdoor activities that are mostly related to dining outside rather than just eating and drinking indoors. This gives restaurants and cafes a big benefit and a large number of customers.

\subsubsection{Saudis Travelling Aboard and Openness to Global Culture}

With the increase of Saudi's traveling abroad, a lot of Saudis are getting exposed to new cultures. Some of which effects their taste and total satisfaction. This sets high benchmarks to follow for local investors but also helps in new ways of investing like franchising restaurants and cafes or taking a worldwide idea and distributing it to locals.

\subsection{Seasonality and Tourism}

The demands of restaurants in Saudi Arabia is normally constant, however, it increases in at certain seasons: (i) Holidays, weekends, and summer vacations represent the highest opportunities where demand is really increased. (ii) Ramadan is a holy month of fasting for Muslims when Saudis love to make charity, so they buy a lot of meals from restaurants in order to provide poor families with good breakfast. Additionally, timing of kingdom is completely changed to fit breakfast time, where Saudis hang out from 9:00 P.M. to 3:00 A.M. Thus, restaurants offer special Ramadan menus for Sahour (supper) and another menu for breakfast (Fatour) to consumers who prefer taking meals away rather eating in restaurants.

(iii) Hajj is a great period when international Muslims come from different areas to do this duty. Restaurants in Makkah witness a prosperous season, where the demand dramatically increased 10 times. According to Al Aziziyah province, the second largest area in Makkah, where its restaurants generated more than 40 million SR during Hajj (www.al-madina.com, 2014). Therefore, religious tourism in Makkah and Al Medina contributes a lot to Saudi economy. (iv) Other occasions are like Eid, National Day, Al Jenadrih festivals, Albujairi festivals, birthdays, graduations parties. Most of Saudi people like to go out for special occasions and celebrate. That is very beneficial for restaurants because they get more customers in those special times.

\section{Strategic and Tactical Issues in Managing Restaurants:}

\subsection{Restaurants Strategy}

Restaurants strategies vary in Saudi Arabia according to the facilities and capital fund of the restaurants. Therefore, restaurants follow one of the three famous strategies: cost leadership, 
differentiation, and focus on niche. (i) Cost leadership strategy followed by majority of Saudi restaurants such as: Sandwich bars, traditional restaurants, and some fast food restaurants where affordable prices are offered for good quality food. (ii) The second segment of restaurants follows differentiation strategy such as: Piatto, Apple Bee's, and Steak House where prices are a bit higher for food. (iii) The remaining segment focuses on niche such as high class restaurants like Spazio where restaurants serve high class customers.

According to a conducted study by Chamber of Commerce and Industry in Riyadh; where $97 \%$ of restaurants capital fund does not exceed million SR, the net income of $85 \%$ of these restaurants does not annually exceed 500,000 SR, and finally $90 \%$ of restaurants rent their headquarters while the remaining restaurants owned them (www.archive.aawsat.com, 2010). As it for future planning strategies; the study indicates that just $35 \%$ of restaurants have clear plans toward expansion and open new branches and just 20\% of restaurants apply standards of accreditation programs (www.archive.aawsat.com, 2010).

There are three types of investment models for restaurants market as it explained in \{Feasibility Assessment for Entry into Saudi Arabia's Services Sectors\}: independent owners, international franchise, and local restaurants chains; see figure 3 ((JETRO), 2015).

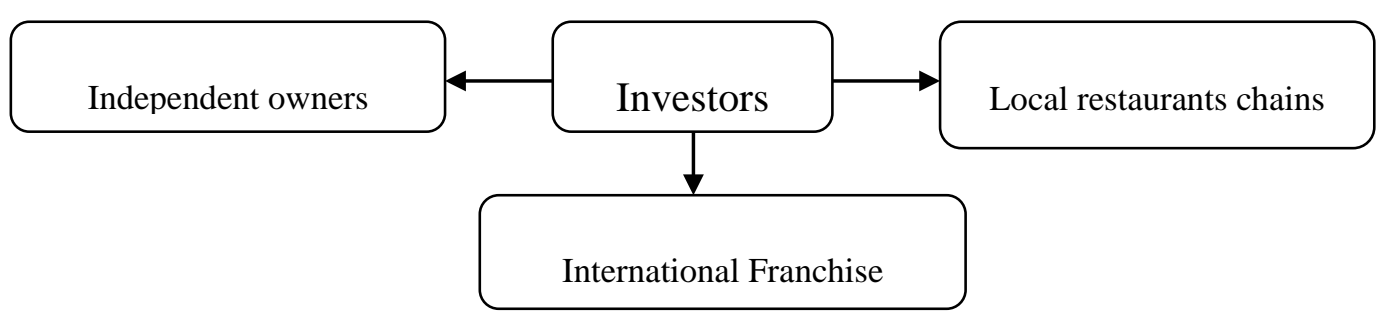

Source: Feasibility Assessment for Entry into Saudi Arabia's Services Sectors.

Figure 3. Investment Model for Restaurants in Saudi Arabia

Technologically, the well- known Saudi restaurants and franchises like Kudu, Herfy, Maestro Pizza, MacDonald's, Domino’s Pizza, and Applebee’s use many MIS systems to organize their operations like sales, production, marketing, and inventory. MacDonald's itself uses multiple technology's like: Transaction Processing Systems (TPS), Decision support systems (DSS), Management Information Systems (MIS), "Made for you” systems, POS system "Scale of Point system ", and Hyperactive Bob systems all to organize its operations and to earn a competitive advantage among peers. These systems are applied in all their branches around the world. Other local restaurants that are not well known or are maintained from home businesses or small shops lack organization and use very basic approaches in managing operations like: Ful, Tamis \& Kibda shops located in each neighborhood, traditional restaurants, Home catering through social media and restaurant carts.

\subsection{Pricing Strategy}

Municipalities of different geographical regions in Saudi Arabia always pay an intensive attention to clean and health issues of almost all Saudi restaurants. However, there are many 
inquiries by Saudi consumers/customers about who is responsible for controlling and monitoring rapid increase of meals prices in restaurants? Still the answer is not neither clear nor known! Ministry of Commerce and Industry admitted that there is an increase in prices, on the other hand, it disclaimed its validity to intervene in such issues (www.aleqt.com, 2012) Nevertheless, restaurants try to justify the increase by attributing that to the rise in operating costs and labor wages. Simply the prices of restaurants are not following defined rules or regulations by governmental parties. Under this respects, consumers find themselves among two choices either to accept the situation or look for substitutes that provide much more affordable prices.

On the positive side, the Ministry of Commerce and Industry intervened when restaurants levied service charge to Saudi consumers in 2012, it appealed them to exclude it on purpose of consumers' safeguard. Some restaurants did not find that announcement fair especially for those fine dining restaurants providing distinctive services. Therefore, some restaurants tend to exclude that charge and at the same time rise the prices. At the end consumers/customers are the victims of such unethical behaviors. Notably, traditional restaurants are increasing their prices comparable to other restaurants; particularly restaurants specialized in rice meals. Surprisingly, what has noticed by Saudi consumer's behavior is albeit this increase in prices, Saudi families still consume within the same consumption patterns! Thus, that what encourages restaurants to do such practices of increasing prices. In addition, in 2018 Saudi government imposed Added Value Taxes (AVT) on all Saudi restaurants which leads to overall increase in pricing systems.

\subsection{Distribution Channels}

Restaurants seem to become more widespread and popular everywhere in Saudi Arabia due to the rapid increase of consumers' demands. They are not exclusively existed at public areas in touristic or commercial zones; they also extend to take a place on main streets and neighborhoods. Surprisingly, the variety and the existence of restaurants would exceed even schools, hospitals, drugstores and gas stations in KSA.

As represented in figure 4 (Restaurants Distribution Channels in Saudi Arabia) adopted from website: (http://agriculture.vic.gov.au/_data/assets/image/0018/233127/fig1_channels.jpg); there are four distributing channels in which food services and restaurants introduce different services to the consumers/consumers (agriculture.vic.gov.au/agriculture, 2018).

(i) Consumers can obtain their meals orders according to the purpose of the needs. Therefore, some consumers prefer to take away their meals to home and consume them indoors. Many restaurants in KSA provide a window services where cars pass by a window, then make their orders and finally take their meals. Many fast food restaurants introduce this service plus delivery service where consumers call the restaurants, then place their orders, and finally restaurants in their turn deliver to consumer's homes. Finally online delivery service is still relatively new in KSA and has restricted to a few restaurants, therefore, it really will have a promising future. 


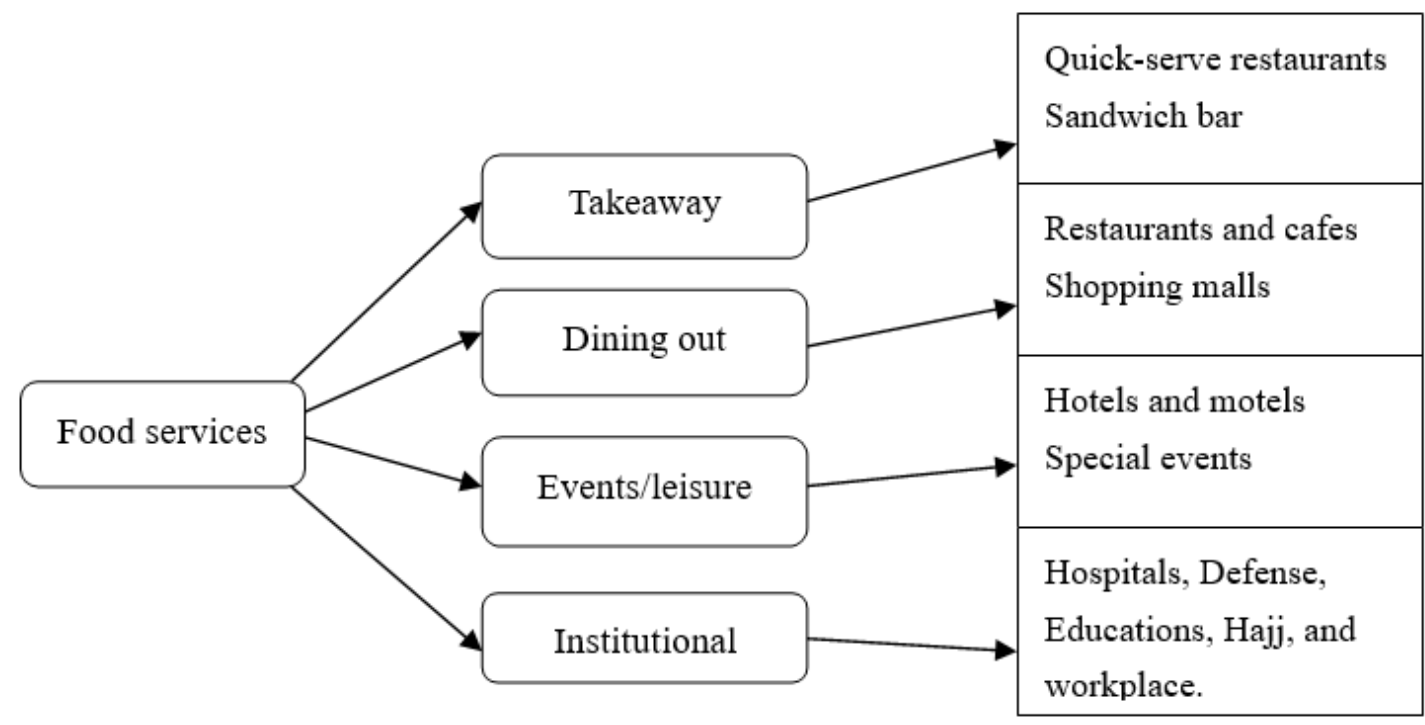

Source: http://agriculture.vic.gov.au/_data/assets/image/0018/233127/fig1_channels.jpg

Figure 4. Restaurants Distribution Channels in Saudi Arabia

(ii) Saudi family is oriented toward dining out as a type of an entertaining activity. Firstly restaurants were providing meals in separate entities in the main headquarters. Almost all restaurants have specified an area for family and another one for male individuals. In 2000, one apparent phenomenon starts to be widespread is the emergence of restaurants inside shopping malls and other closed areas like universities and amusement parks.

(iii) Hotels offer various food services like buffets where consumers can pick up their food from a collection of different dishes. Some hotels provide food services to different types of parties. It is clear that Saudis have a lot of special events like weddings, birthday parties, graduation parties, and Eid. Under this respect, Saudis are fond of a lavish style of parties, where they like very impressive and expensive ways of serving food in new styles thus, hotels provide them by such services.

(iv) The majority of Saudi institutions outsources their food services and depends on catering companies for that. For instance, King Saud University (KSU) contracts with Gulf Catering Company to provide students and staff with two meals (breakfast and lunch) daily in the university restaurants. This same company (GCC) also caters for ministry of defense in KSA. Additionally, Al Baik restaurant provides catering services for pilgrims at Hajj period since almost 14 years.

\subsection{Promotion}

Although restaurants accomplish successful and financial investment, they still lack organized and arranged marketing campaigns and adequate advertisements. 85\%, restaurants which are the majority of them are owned by independent individuals. $61 \%$ of them do not unitize professional methods of advertising (www.archive.aawsat.com, 2010). Thus, they use 
simple traditional methods like disseminating the menus in neighborhoods, posting advertisements in newspapers, flyers, and finally small talks of consumers' opinions and experiences in the taste or provided services may also have great effects in marketing restaurants.

On the other hand, there are some new trends in marketing restaurants in Saudi Arabia like celebrity endorsements, word of mouth, and social media marketing. (i) Celebrity endorsements; this approach is used by well-known people who increase Saudis awareness of some restaurants services and offers. Afnan AlBatel and Noha Nabel whom have more the 1 million followers in social Medias are one of the famous celebrities in KSA. (ii) There are some great efforts of anonymous individual channels where they aim to classify restaurants according to consumers/customers preferences. It is really a helpful means to know about the services from words of mouth. (iii) Social media marketing; is the most used concepts where restaurants market themselves through different electronic websites: Facebook, Twitter, Instigram, Snapchat, and so on. Ultimately, there are other accounts like Althawagah (Tasters) with more than $250 \mathrm{~K}$ followers promote for restaurants through reports and assessment of restaurants.

\section{Saudi Restaurants Industry Classification by Services}

Saudi food services are segmented into four major classes: (i) Full services restaurants; (ii) Fast food restaurants; (iii) Traditional restaurants; (iv) Cafes ((JETRO), 2015). See figure 5 (Saudi Food Service Industry) which adopted from \{Feasibility Assessment for Entry into Saudi Arabia's Services Sectors\}. Of course, fast food restaurants represent the large investment domain for both franchising and local branding restaurants chains. Under this respect, this case study investigates some famous successful restaurants in KSA.

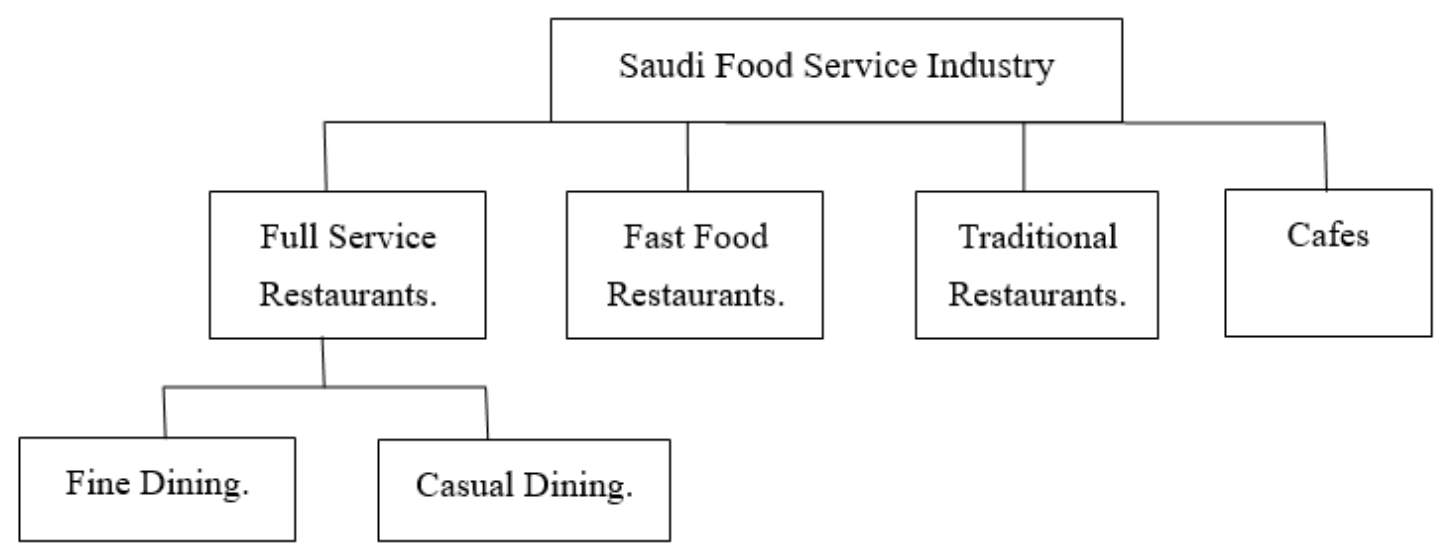

Source: Feasibility Assessment for Entry into Saudi Arabia's Services Sectors

Figure 5. Saudi Food Service Industry

\subsection{Full Service Restaurants}

Under the first segment; the full service restaurants divide for two main parts fine dining restaurants and casual dining restaurants. 


\subsubsection{Fine Dining Restaurants}

This kind of restaurants are characterized by high quality services provided by professional staff and serve expensive food prices. More importantly, they focus on working with (niches) or high class clients, thus, honorable decorations and styles are highly required to satisfy their customers. Here are two examples of fine dining restaurants:

\section{The Grill Restaurant}

The Grill restaurant reflects the spirit and energy of the flourishing international business city of Riyadh in its contemporary design with a traditional twist, including new Majlis-style seating with low cushions and tables. Guests are invited to select from an à la carte menu featuring a wide variety of imported meats, fish and fresh seafood, all prepared and grilled to their preference in a semi-open kitchen. Premium steaks are a highlight of their grill menu, while an express business lunch menu will feature a choice of appetizer, main course and dessert, all served within 45 minutes. In the cooler months, the Terrace and Terrace BBQ open as an extension to the restaurant (www.fourseasons.com, 2018).

\section{Spazio}

It opens in 2003; Spazio has built its reputation as the place to go for exceptional fine dining in Riyadh, with a unique ambiance which could not be matched anywhere else in the city. Spazio has become the place to see and be seen, having the honor of hosting prestigious clients from around the world including members of the Royal Family, Presidents, Prime Ministers, and famous artists. Spazio has redefined fine-dining with its contemporary design using warm and natural colors, stylish furniture, and intimate lighting (www.spazio77.com., 2018).

\subsubsection{Casual Dining restaurants}

This kind of restaurants are characterized by moderate prices and good services quality. Normally, they are collective of fine dining and fast food restaurants, however they are less expensive than fine dining restaurants.

\section{Apple Bee's}

Applebee's Grill and Restaurant is the world's largest casual dining restaurant company. With more than 2,100 restaurants in 19 countries around the globe, it is a well-recognized brand and a leader in the casual dining segment. Applebee's opened its first restaurant in Jeddah in 2003. AECL owns the franchise rights in the Kingdom of Saudi Arabia. It currently operates restaurants in all major cities in KSA with further expansion plans into other potential markets (www.applebeesksa.com, 2018).

\section{Steak House}

Steak House first opened its doors two decades ago in a modest, 60-seater restaurant at Olaya-Thalatheen in Riyadh. Today, Steak House operates 12 conveniently-located branches 
throughout the Kingdom of Saudi Arabia and has become the most popular casual-dining chain in the country (www.applebeesksa.com, 2018).

\section{Chili's}

Chili's is an American casual dining restaurant chain. It was franchised in Saudi Arabia by Arabian Food Supplies with the opening of its first restaurant in Jeddah in 1999. There are eight branches in Saudi Arabia including Jeddah, Riyadh, Alkhobar, Dhahran, Medina and Jubail. Chili's offers a US south-western cuisine with variety of sizzling dishes, appetizers, thirst-quenching drinks and decadent desserts.

\subsection{Fast Food Restaurants}

This kind of restaurants are characterized by affordable prices and have the highest portion of Saudi customers/consumers which accounts about $60 \%$. Here are some famous restaurants of fast food:

\section{McDonald's}

McDonald's is the world's largest chain fast food restaurant serving around 68 million customers daily in 119 countries across more than 36,000 outlets. It was founded in the United States in 1940. Now McDonald's restaurant is operated by a franchisee, an affiliate, or the corporation itself.

McDonald's restaurants in the KSA is locally owned and operated by two exclusively franchisees. The first company is "Riyadh International Catering Company" that represents McDonald's in the Central, Northern, and Eastern regions of the kingdom beside "Reza Food Services Co. ltd" that represents the Western and Southern regions of the Kingdom. McDonald's was introduced to the Saudi market in 1993. There are more than 200 branches across the kingdom. McDonald's offers a variety of burgers in different recipes, and an Arabian twist for the burger. It offers breakfast menu and coffee selections for morning people too.

\section{Herfy}

Herfy is one of the well-known restaurants in the kingdom. It was co-founded in 1981 by Ahmed Bin Hamad Al-Said who partnered with Panda United to open the first branch in Riyadh. Later, Aziza Panda launched a partnership with Savola group that operated Herfy in 1998. However, in 2008 Herfy Food Services Company, Ltd. has become a closed joint stock company continues with this success. It floats $30 \%$ of its shares for public subscription and joined Saudi Stock Market. Herfy branches are all over Saudi Arabia along with Bahrain, United Arab Emirates, Kuwait, Egypt, and Lebanon. Herfy restaurants offer burgers, sandwiches, chicken, ice cream and milkshake. Herfy restaurants control and maintain its quality and ingredients by using all needed ingredients that produced by the mother company as food service company (www.herfy.com, 2018). 


\section{Pizza Hut}

Pizza Hut is an American restaurant chain known for Italian-American cuisine including pizza and pasta as well as side dishes and desserts. It is a subsidiary of Yum! Brands, Inc the largest fast-food restaurant company in the world. It opened the first branch in 1987 in Saudi Arabia. It also has 230 branches inside the kingdom by two different franchisees.

\section{Maestro pizza}

Maestro Pizza is one of the fastest growing restaurants in Saudi Arabia. It was established in 2014 in Riyadh, and after two years it has more than 98 branches across Saudi Arabia. It provides a high quality pizza with best ingredients and recipes. It also offers their pizza with reasonable prices. Maestro Pizza changes the Saudi Pizza market, it forces major pizza players in the market (such as Dominos Pizza and Pizza hut) to lower their prices to compete with Maestro Pizza aggressive expansion plan. Maestro Pizza focuses on Saudization policy and tries to gain customer's loyalty through emphasizing on customer satisfaction.

\section{Al-Biak Chicken}

Al Baik is one of the most successful Saudi fast food chains in Saudi Arabia. It established in 1974 by Shakkour AbuGhazalah, and it was the first pressure fried chicken restaurant in Saudi Arabia. The first branch was in Jeddah and then it expanded to more than 41 branches around the kingdom including Medina, Taif, Yanbu, Makkah, Alqunfudah, and the latest branch in Alqassim. Its menu focuses mainly on chicken. Additionally, it introduces shrimps and fish as a seafood selection.

The competitive advantage is the secret recipe that includes 18 secret spices and herbs. It also provides a high quality and affordable prices which seem very pleasing for local consumers. For those reasons, Albaik dominates the market share of fried chicken in the western province. Although there is a huge demand for Albaik across the kingdom, but its expansion is very sluggish, the first branch opened outside the western province was in Alqassim.

\section{Al-Tazaj Chicken}

Al Tazaj is a Saudi BBQ chicken fast food restaurant chain. The first branch was open in Makkah in 1989 by Abdul Rahman Fakieh. Al Tazaj currently has more than 100 branches across the kingdom. Al Tazaj expands globally through franchised in countries like Egypt, UAE, Kuwait, Morocco, Lebanon, Malaysia, USA, and Chad. It offers high quality fresh barbecued chicken in Arabic styles. It focuses mainly on chicken that supplied freshly from Fakieh Poultry Farm.

\section{Kudu}

Kudu is one of the largest fast food chains in Saudi Arabia. It was established in 1988 by Abdul-Mohsen Al-Yahya. The first branch was opened in Riyadh then expanded to Jeddah and Eastern Province. Now it has more than 300 branches around the kingdom. It also expands globally to include GCC, Sudan, Jordan, Libya, and Yemen. It offers a wide range of 
sandwiches, salads, breakfast and launch meals. Its core competency is the freshness and high quality of its ingredients.

\section{Shawarmer}

Shawarmer is the first formalized shawarma sandwich chain in Saudi Arabia. It was established in 1999 by Abdulmohsin Al-Rabiah. The first branch was opened in Riyadh and then expands to Jeddah, Al medina, Eastern province, Al majmah, and Alqassim. The concept of traditional shawrma sandwich is formalized in various flavors to satisfy all consumers' preferences. Shawarmer aims to bring Arabic concept food out to the world in an organized brand and concept.

\subsection{Traditional Restaurants}

This kind of restaurants serves traditional Saudi and Arabic meals with almost averaged prices. However, some restaurants may increase their prices according to provided services and place decoration. Here are some examples of popular traditional restaurants:

\section{Al-Romansiah}

Al Romansiah is one of the leading restaurants for authentic Saudi food. It was established in 1998 and opened its first branch in Riyadh. It has around 17 branches across the Kingdom including Alqassim, Ahssa, and Alkharj. It also plans to expand locally and internationally to include Dammam and Jeddah and to open their first international branch in Bahrain. Alromansiah offers authentic Saudi meals like Kabsa, Mathloutha, grilled chicken, meats, fish, and different types of local Saudi cuisine. It also offers a family section and a VIP dining room besides a regular dining in. It also offers catering services for parties and different events.

\section{Shawaya House}

Shawaya House is one of the well-known restaurants for authentic Saudi food. It was established in 2005 and opened its first branch in Riyadh. Now it has more than 90 branches across the Kingdom. They offer authentic food in an organized open- kitchen concept and fast service. It offers a wide variety of Kabsa, soups, appetizers, and grilled chicken. Its strategy is cost leadership which offers the best quality food with affordable prices for everyone.

\section{Al-Nadeg}

Al Nadeg is one of the Saudi authentic restaurants. It was established in 2002 and opened its first branch in Riyadh. It has only 7 branches in Riyadh and offers a variety of rice dishes and all kinds of meat. It also offers dining in, VIP rooms, delivery, and catering services. It considers one of the leading in the organized authentic and traditional Saudi food.

\section{Cabrito}

Cabrito restaurant is one of the Saudi authentic restaurants. It was established in 2003 in Riyadh and it has only 5 branches. They offer wide selections of rice and meats including 
chicken, lambs, rabbit, and quail. Cabrito offers a new concept where it grills the whole lamb or rabbit in front of customers. It offers dining in, delivery, and catering services where it grills the whole lamb in front of the guests.

\subsection{Cafés}

As for this segment, it was the first real start for restaurants in KSA. As we said before the first cafes in KSA were in Makkah and Al Medina because they were and still exposed to the cultures of international visitors of religious tourism. Cafes were called Mashrab which means (Drinker) a place where Saudis used to drink tea and coffee there (www.alriyadh.com, 2013). Again, they were just for males till the mid of 2000 when families are allowed to visit cafes. Today Cafes shift from traditional drinks like milk-tea to more international drinks like Cappuccino and iced tea. Here are two famous brand cafes in KSA:

\section{Java Time}

Java Time was born of a need for local venues where customers could rely on excellent quality and services along with environment designed to calm and appease them. Before the authentic coffee culture experience was introduced to Riyadh, locals had never considered coffee as anything more than a hot brewed drink, often stale and bitter, purchased from a vending machine, and with very little variety.

Java Time is dedicated to enhancing the lives of its employees with fair compensation and a workplace that fosters self-esteem and self-confidence. it does this by providing a rigorous training program that cultivates team spirit and a sense of ownership, which translates into an authentic and gratifying coffee culture experience for patrons. Undeterred focus on core values, transparency in business practices, and a strong sense of team spirit that drives commitment to customer satisfaction.

Java Time has locations throughout the cities, and because customers have different needs, it offers a variety of retail formats so they can deliver coffee just as the customers like it. With drive-thru cafes that make not even leave your car. There is no quicker way to grab your drink and go. it also has walk-in stores that offer a stress-free environment where you can sit down and watch the world go by. The comfortable furniture and refined decor are designed to compose and relax. All its stores have a no-smoking policy and ample seating. With friendly, courteous staff that cater to your every need. They also have coffee kiosks located in strategic locations, so the perfect cup of coffee is never far away.

\section{Dr. Café Coffee}

Dr Café is one of the leading coffee brands in Saudi Arabia. It was established in 1997 by Yousef Alrajhi who opened its first branch in Alouruba Plaza in Riyadh. Later it was expanding aggressively in the kingdom, planning to reach more than 650 branches at the end of this year 2016. It almost dominates the coffee shops in public and private institutions like universities and hospitals. Also, it has expanded globally through franchising to include Malaysia and Singapore. Dr Café offers different kinds of coffee as well as sandwiches and 
sweets. It provides high quality services that mainly justify its higher price.

\section{New Trends Derived from Restaurants Growth in Saudi Arabia}

\subsection{Shifts toward Diet Centers and Healthy Food}

Consumers of fast food and restaurants meals become much more aware of the importance of eating healthy food. Under the increase of obesity and health problems in Saudi Arabia, there is a need for satisfying consumers' requirements by offering those healthy meals that keep them on attractive figures and being healthy. Diet Center is the first accredited center which took that into consideration in Saudi Arabia since 1996. It offers its menu according to the good nutrition guidelines of the American Dietetic Association and the American Heart Association (www.dietcenter.com, 2018). Now it has more than 40 branches widespread in all large Saudi cities. Additionally, some Saudi restaurants start to target healthy eaters by providing them with fitness meals. This kind of restaurants varies in their services such as $\mathrm{Al}$ Tazj, Quiznos Sub, Diet Delite, Mega Wraps, Pinkberry, and Subway.

\subsection{Electronic Restaurants through Social Media}

Due to Saudi women strong local entrepreneurial instincts, the use of social media has changed to be exploited and utilized in electronic restaurants trades. Many Saudi women shift toward cooking food and selling it through the social media. This segment competes even for attractive restaurants and catering food services. The purposes of cooking differ according to the demands of customers where some of them order traditional Saudi and Arabic food, fish, Pasta, Salads, and different types of appetizers.

Generally, each cook specialized in one type of food for example: "Finding Sushi" is a business conducted by two entrepreneurial Saudi businesswomen that love sushi; they started their business by home delivery orders and event catering with wonderful sushi bars and great service. Due to the large demand on their products and services and large income now they are going to open their first branch on Olaya Street. They use multi social media ways of communication like: Instagram, Twitter, Facebook, Snapchat, and their very own website "http://www.finding-sushi.com" to communicate with customers. Their business is very wellorganized and wonderfully managed (www.finding-sushi.com, 2018).

Saudi women found a business game by which they can spend their free times and generate money from it. It is noticeable that these chefs are famous for capability to cook professionally and that what leads to higher demands on their services. Another thing makes this phenomenon increasing in Saudi Arabia; there are no commercial requirements for market entry.

\subsection{A Movement toward Fully Female-Services Restaurants}

A new trend in Saudi Arabia is a fully female restaurant. Earlier, it was not accepted by Saudi culture for woman to dine out or order catering from restaurants. A Saudi woman was responsible for providing her family and guests with meals without any external helps. 
Recently, The Ministry of Labor has decided to allow Saudi women to become chefs at hotels, this indicates the recognition and change in the society toward Saudi female working in this sector (www.arabnews.com, 2015).

The emergence of this trend has increased in the last decade with female chefs running their own catering services from home. For instance, "Almaedah Altaybah" where established in Riyadh by two female chefs Aziza Alyousf and Nawal Alswaydan where it was a home-based catering service. Later, they open their public restaurant with male staff to run it. However, other female entrepreneurs such as Hanan Alenzi opened her first restaurant in Riyadh "Santwa" which offers a wide variety of cuisines and fancy dining at atmosphere with fully female staff; her restaurant considers the first licensed fully female restaurant in the kingdom.

Another example is "Snafiat" restaurant in Onizah-Alqassim which considered being one of its kind in Alqassim where female guests can dine in the restaurants and be served by fully female staff. However, most of the female restaurants are concerned only with delivery and catering service such as the famous female restaurant "Nouryat" in Dammam. Also, there is a fully female restaurant opened in Alqataif to serve its customers during the lunchtime only, the staff is fully female and serve both males and females for take away orders. The fully female trend is disseminated all over the kingdom with different concepts.

\section{Challenges Affecting Restaurants}

There are some challenges confronting Saudi restaurants industry. Under this point, the most obvious challenges are: stiff competition and Saudization policy, increase in inflation rate and life expenditures, healthy problems and obesity.

\subsection{Stiff Competition and Saudization Policy.}

Studies have shown that there is a high degree of competition between restaurants, and that competition increases or decreases according to the most important factors attracting customers such as: the quality of food, the location, the equipment used the furniture, and nationality of the workers.

It is important to mention that: "The catering and restaurant subsectors are very price sensitive, due to the stiff competition that prevails in the market. Catering companies and fast food chains compete on both prices and quality.” For example MacDonald's is one the major player restaurants that supplies good food with very reasonable prices and low costs. There is also stiff competition among both local and foreign restaurants if we take the Pizza sector as an example; we have Maestro Pizza as a local Pizza restaurant that is fiercely competing among Domino's Pizza a foreign restaurant in: recipes, services, and prices. With larger competition and more costumers' demands that leads to open more branches of restaurants and urgent need to employ more workers.

Saudi Arabia applied a Saudization policy in all sectors including the food industry. Restaurants where forced to employ Saudis in all its levels of operations like serving food to tables as waiters which made a lot of Saudi youth repulse from working in that sector due to 
the customs and traditions of the community. Table 4 (Number of Saudi and Non-Saudi employees in Restaurants Sectors) indicates updated information about restaurants employees in Saudi Arabia which adopted from website (www.stats.gov.sa/ar, 2018).

Table 4. Number of Saudi and Non-Saudi employees in Restaurants Sectors

\begin{tabular}{|l|c|c|c|}
\hline & Male & Female & Total \\
\hline Saudi employees & 25,330 & 7,337 & 32,660 \\
\hline Non-Saudi employees & 237,768 & 4,166 & 241,906 \\
\hline Total & 263,099 & 11,506 & 274,566 \\
\hline
\end{tabular}

Source: http://www.stats.gov.sa/ar

\subsection{Increases in the Inflation Rate \& Life Expenditures.}

Saudi economists refer to the unbalanced gap between the increase of goods costs and the individual income. While the first rises dramatically by $700 \%$, the second grows sluggishly by 66\% (www.aleqt.com, 2012). This discrepancy may lead to economical catastrophes, especially in a consumed-based country like Saudi Arabia. Under this respect, if that problem is not taken seriously by governmental agencies, it would affect society-wellbeing and economic growth. The inflation rate increases twice from 2.3\% in Dec. 2015 to 4.3\% in Feb. 2016 (www.sama.gov.sa, 2018). In addition, there was a dramatic increase in gas, electricity and water costs which could lead to an increase in operating costs for restaurants in the future.

\subsection{Healthy Problems and Obesity.}

Experts examined the relation between eating at restaurants and obesity found that the more you eat out, the more likely you are to be obese. According to a research conducted by King Saud University, found that $70 \%$ of Saudi males and $75 \%$ of Saudi females are obese (www.arabnews.com, 2016). Obesity is not just the problem, a variety of other health problems attached to the increased of consuming habits of unhealthy food. These problems may arise due to the low nutritional values, the high fats, calories and sodium contents in the meals.

\section{Where Are the Restaurants Headed To?}

Many Saudi experts and researchers anticipate that there will be 5\% growth in restaurants and cafes industry because Saudis consume more than 8 million meals monthly. Additionally, there is a study shows that the industry of restaurants in Saudi Arabia achieved the most rapid growth in the Middle East due to social, cultural, and economic changes. Thus, it is very important to improve this sector and provide qualified training programs for employees. Also municipalities should activate accreditation systems in order to improve skillful and scientific 
performance, and increase the awareness of healthy concept in food production inside restaurants.

The activities of restaurants sectors is not restricted on traditional restaurants that just serve food, it includes other activities like catering companies, kitchens that cooked for parties, ice-cream and juice shops. According to General Authority for Statistics (http://www.stats.gov.sa/ar); there are almost 16 activities that restaurants sector offers in table 5 (Restaurants Sector Activities in Saudi Arabia). Mainly, this indicates the diversified functions of restaurants sectors and its fast expansion over all Kingdom of Saudi Arabia.

Table 5. Restaurants Sector Activities in Saudi Arabia.

\begin{tabular}{|l|c|}
\hline \multicolumn{1}{|c|}{ Restaurants activities } & Total \\
\hline Restaurants with the services & 15,839 \\
\hline Cafeterias & 26,994 \\
\hline Fast Food Restaurants & 8,834 \\
\hline Pizza Restaurants (Take out) & 216 \\
\hline Serving Food Restaurants & 811 \\
\hline Food Preparation Kiosk & 379 \\
\hline Food Preparation companies & 218 \\
\hline Kitchens of Preparing Banquet and parties & 3,231 \\
\hline Other food services & 115 \\
\hline Serving Beverages shops & 252 \\
\hline Coffee shops & 3,500 \\
\hline Traditional cafes & 197 \\
\hline Cafes serving Shisha (hubble-bubble) & 933 \\
\hline Internet-Cafes & 562 \\
\hline Ice-cream shops & 634 \\
\hline Juice shops & 569 \\
\hline Total & 63,284 \\
\hline
\end{tabular}

Source: http://www.stats.gov.sa/ar

\section{References}

(JETRO), J. E. (2015). Feasibility Assessment For Entry into Saudi Arabia's Services Sectors. agriculture.vic.gov.au/agriculture. (2018, Mar.). Retrieved Mar. 2018, from agriculture.vic.gov.au: http://agriculture.vic.gov.au/_data/assets/image/0018/233127/fig1_channels.jpg arabic.arabianbusiness.com. (2016, Jan). Retrieved Mar. 2018, from arabic.arabianbusiness.com: http://arabic.arabianbusiness.com/politics-economics/2016/jan/9/404406 
Assad, S. W. (2008). The Rise of Consumerism in Saudi Arabian Society. Journal of Commerce and Management, 17(1/2), 73-104. https://doi.org/10.1108/10569210710774767

Kukko, R., \& Al-Aali, A. (2015). What, Who, How and Where: Retailing Industry in Saudi Arabia. Journal of Competitiveness Studies, 23(3), 54-69.

Tunclap, S. (1991). Problems and Prospects for Franchising in the Arabian Peninsula: the Case of Saudi Arabia. international journal of retail \& distribution management, 19(4), pp.28-37. https://doi.org/10.1108/09590559110000637

www.aleqt.com. (2012, Oct.). Retrieved April 2018, from www.aleqt.com: http://www.aleqt.com/2012/10/15/article_701662.html

www.al-madina.com. (2014, Oct. 15). Retrieved April 2018, from www.al-madina.com: http://www.al-madina.com/node/563100

www.al-madina.com. (2014, Oct. 25). Retrieved April 2018, from www.al-madina.com: http://www.al-madina.com/node/565296

www.alriyadh.com. (2012, April). Retrieved April 2018, from www.alriyadh.com: www.alriyadh.com/726673

www.alriyadh.com. (2013, July). Retrieved April 2018, from www.alriyadh.com: http://www.alriyadh.com/854570

www.alriyadh.com. (2014, Dec.). Retrieved April 2018, from www.alriyadh.com: http://www.alriyadh.com/1002988

www.alriyadh.com. (2014, Sept. 16). Retrieved Mar 2018, from www.alriyadh.com: www.alriyadh.com/976708

www.alriyadhtrading.com. (2018, April). Retrieved April 2018, from www.alriyadhtrading.com: http://www.alriyadhtrading.com/show_content_sub.php?CUV=54\&Model=\&SubModel=11 \&ID=1595\&ShowAll=On

www.applebeesksa.com. (2018, Mar.). Retrieved Mar 2018, from www.applebeesksa.com: http://www.applebeesksa.com/aboutus.html

www.arabnews.com. (2015, June 23). Retrieved April 2018, from www.arabnews.com : http://www.arabnews.com/news/766186

www.arabnews.com. (2016, Jan. 3). Retrieved April 2018, from www.arabnews.com: http://www.arabnews.com/saudi-arabia/news/859546

www.archive.aawsat.com. (2010, May 20). Retrieved April 2018, from www.archive.aawsat.com:

http://archive.aawsat.com/details.asp?issueno=11700\&article $=570270 \# . V w j W R \_k r L I U$ 
www.argaam.com. (2017, May 26). Retrieved Mar. 2018, from www.argaam.com: https://www.argaam.com/ar/article/articledetail/id/488235

www.cnbcarabia.com. (2014, May 6). Retrieved Mar. 2018, from www.cnbcarabia.com: http://www.cnbcarabia.com/?p=151927

www.dietcenter.com. (2018, April). Retrieved April 2018, from www.dietcenter.com: http://www.dietcenter.com.sa/about.html

www.finding-sushi.com. (2018, Mar.). Retrieved Mar. 2018, from www.finding-sushi.com: http://www.finding-sushi.com

www.fourseasons.com. (2018, Mar.). Retrieved Mar. 2018, from www.fourseasons.com: http://www.fourseasons.com/riyadh/dining/restaurants/the_grill/

www.herfy.com. (2018, April). Retrieved April 2018, from www.herfy.com: http://www.herfy.com/ar/about.php

www.sama.gov.sa. (2018, Mar.). Retrieved Mar. 2018, from www.sama.gov.sa: http://www.sama.gov.sa/en-US/Pages/default.aspx

www.slaati.com. (2015, June 10). Retrieved April 2018, from www.slaati.com: https://www.slaati.com/2015/06/10/p350237.html

www.spazio77.com. (2018, Mar.). Retrieved Mar. 2018, from www.spazio77.com.: http://www.spazio77.com

www.stats.gov.sa/ar. (2018, Mar.). Retrieved Mar. 2018, from www.stats.gov.sa/ar: http://

www.steakhouse.com. (2018, Mar.). Retrieved Mar. 2018, from www.steakhouse.com: http://www.steakhouse.com.sa/aboutus/\#.VyeiymOKdPM

\section{Copyright}

Copyright for this article is retained by the author(s), with first publication rights granted to the journal.

This is an open-access article distributed under the terms and conditions of the Creative Commons Attribution license (http://creativecommons.org/licenses/by/4.0/). 